\title{
Penerapan Metode Metode Multi-Attribut Border Approximation Area Comparison (MABAC) dalam Penentuan Akademi Kebidanan (AKBID) Terbaik
}

\author{
Rizki Dermawan, Sinar Sinurat \\ Fakultas Ilmu Komputer dan Teknologi Informasi, Prodi Teknik Informatika, Universitas Budi Darma, Medan, Indonesia \\ Email: ${ }^{1}$ rizkidermawan310@gmail.com \\ Submitted: 26/07/2021; Accepted: 13/11/2021; Published: 30/11/2021
}

\begin{abstract}
Abstrak-Akademi Kebidanan (AKBID) adalah salah satu pilihan untuk melanjutkan pendidikan pasca sarjana, terutama di kota Medan. Akademi kebidanan swasta yang berkualitas sangat mempengaruhi dalam mejalani suatu pendidikan. Agar mudah bersaing didalam dunia kerja. Karena AKBID yang baik sudah pasti akreditasinya juga baik, akreditasi AKBID sangatlah berpengaruh dalam dunia kerja. Terutama dalam jenjang karir, penerimaan tenaga kerja baru. Dalam penentuan AKBID di kota medan ini tidaklah mudah, di karenakan banyaknya AKBID yang ada di kota medan. Terlalu banyaknya AKBID yang ada, membuat sulit dalam penentuan AKBID secara manual dilakukan, dan hasil pemilihan terkadang kurang tepat dan menjadi suatu permasalahan dalam penentuan AKBID terbaik. Sistem Pendukung Keputusan (SPK) adalah sistem yang dapat membantu seseorang dalam mengambil keputusan yang akurat dan tepat sasaran.Metode yang digunakan dalam Sistem Pendukung Keputusan adalah dengan menggunakan Multi-Attributive Border Approximation Area Comparison (MABAC).Metode ini dipilih karenadapat membantu proses pengambilan keputusan penentuan akademi kebidanan dengan optimal, dalam hal ini alternatif yang dimaksudkan yaitu yang berhak menjadi Akademi Kebidanan terbaik berdasarkan kriteria yang ditentukan.
\end{abstract}

Kata Kunci: Akademi Kebidanan; Sistem Pendukung Keputusan; MABAC

Abstract-The Midwifery Academy (AKBID) is one of the options for continuing post-graduate education, especially in the city of Medan. A quality private midwifery academy greatly influences the course of an education. To easily compete in the world of work. Because a good AKBID has a good accreditation, AKBID accreditation is very influential in the world of work. Especially in the career path, acceptance of new workers. Determining the IMR in the city of Medan is not easy, because there are many IMRs in the city of Medan. There are too many IMRs available, making it difficult to determine the IMR manually, and the election results are sometimes inaccurate and become a problem in determining the best IMR. Decision Support System (DSS) is a system that can assist a person in making accurate and targeted decisions. The method used in the Decision Support System is to use Multi-Attributive Border Approximation Area Comparison (MABAC). This method was chosen because it can assist the decision-making process determining the optimal midwifery academy, in this case the intended alternative is the one who has the right to become the best Midwifery Academy based on the specified criteria.

Keywords: Midwifery Academy; Decision Support System; MABAC

\section{PENDAHULUAN}

Adanya teknologi sangat membantu kehidupan manusia dalam melaksanakan berbagai pekerjaan mereka. Teknologi membuat manusia tidak merasa kesulitan, sehingga memudahkan pekerjaan mereka. Komputer merupakan alat yang biasanya dipergunakan untuk mengolah data berdasarkan aturan baku yang sudah ditentukan. Perkembangan komputer masa kini begitu cepat dan semakin mudah digunakan oleh banyak kalangan. Setelah melawati sederetan perjalanan panjang, computer dimasa sekarang ini lebih maju ketimbang pendahuluannya.

Akademi Kebidanan (AKBID) adalah salah satu pilihan untuk melanjutkan pendidikan diploma. Bidan adalah seorang wanita yang telah menyelesaikan program pendidikan kebidanan yang diakui oleh Negara dan memenuhi kualifikasi untuk daftar serta memiliki izin yang sah untuk menjalankan praktek kebidanannya. Pada masa kini akademi kebidanan sangatlah diminati oleh masyarakat, Sehingga banyak masyarakat yang memilih akademi kebidananya masing-masing untuk dapat menambah ilmu dan menjadi seorang bidan yang baik. Dalam menentukan akademi kebidanan yang baik tidaklah mudah, dikarenakan banyak nya akademi kebidanan di sumatera utara ini khusus nya di Kota Medan. Sehingga membuat sulit dalam menentukan akademi kebidanan yang masih dilakukan manual, selain itu hasilnya kadang kurang tepat sehingga menimbulkan permasalahan.

Berbagai macam cara sudah dilakukan dalam penentuan AKBID terbaik yang bertujuan untuk mengembangkan pendidikan. Selama ini dalam menentukan AKBID terbaik masih dilakukan secara manual dan tidaklah muda, terkadang dalam penentuan secara manual menghasilkan hasil yang tidak tepat dan kurang sistematis. Karena setiap AKBID mempunyai akreditas dan fasilitas yang berbeda-beda. Dan membuat lambat dalam penentuan AKBID terbaik yang ada di kota medan ini jika masih di lakukan secara manual.

Sistem Pendukung Keputusan atau Decision Support Systems merupakan sistem informasi interaktif yang menyediakan informasi, pemodelan, dan manipulasi data. Sistem ini digunakan untuk membantu pengambilan keputusan dalam situasi yang semiterstruktur dan situasi yangtidak terstruktur, dimana tak seorang pun tahu secara pasti bagaimana keputusan seharusnya dibuat [1], [2]. Metode Multi-Attributive Border Approximation Area Comparison $(M A B A C)$ merupakan metode perbandingan multikriteria. Metode ini dipilih karena, metode ini menyediakan stabil (konsisten) solusi dan handal untuk pengambilan keputusan rasional, dibandingkan dengan metode lain multi-kriteria pengambilan keputusan (SAW, COPRAS, MOORA, TOPSIS dan VIKOR) [3]. 


\section{METODOLOGI PENELITIAN}

\subsection{Sistem Pendukung Keputusan}

Sistem Pendukung Keputusan (SPK) atau Decision Support System (DSS) adalah sebuah sistem yang mampu memberikan kemampuan pemecahan masalah maupun kemampuan pengkomunikasian untuk masalah dengan kondisi semi terstruktur dan tak terstruktur. Sistem ini digunakan untuk membantu pengambilan keputusan dalam situasi semi terstruktur dan situasi yang tidak terstruktur, di mana tak seorangpun tahu secara pasti bagaimana keputusan seharusnya dibuat [4], [5].

\subsection{Akademi Kebidanan (AKBID)}

Pendidikan Kebidanan bertujuan untuk menghasilkan bidan. Pendidikan Kebidanan di perguruan tinggi di Indonesia sudah ada sejak 1996 dan semakin berkembang pada tahun 2008 hingga tahun 2012. Pada Tahun 2008 hingga 2013, perkembangan pendidikan kebidanan semakin signifikan yakni dibukanya program S1 dan S2 di beberapa perguruan tinggi negeri. Pendidikan Kebidanan mulai bersaing secara profesional dengan pendidikan kesehatan lainnya seperti Pendidikan Kedokteran, Ilmu Keperawatan dan Farmasi yang telah lebih dahulu memiliki program studi pada jenjang S1, S2 bahkan Spesialis (Sp-1 dan Sp-2) hingga doktoral. Uniknya, Program Studi Magister Kebidanan (S2) lebih dahulu dibuka ketimbang Program Studi Sarjana Kebidanan (S1). Hal ini untuk segera memenuhi tuntutan bahwa seorang dosen di perguruan tinggi minimal berpendidikan S2. Semua akademi kebidanan di Indonesia dikoordinasikan oleh badan yang disebut LLDIKTI. LLDIKTI (Lembaga Layanan Pendidikan Tinggi) di bawah KEMENRISTEK DIKTI dan dibagi pada setiap wilayah masing-masing.

\subsection{Metode Multi Attributive Border Approximation Area Comparison (MABAC)}

Metode MABAC adalah singkatan dari multi-attributive border approximation area comparison. MABAC meruapakan metode perbandingan multikriteria. Metode ini dipilih karena metode ini menyediakan stabil (konsisten) solusi dan handal untuk pengambilan keputusan rasional. Prinsip pilihan adalah sebuah kriteria yang menggambarkan akseptabilitas dari sebuah (kemampuan untuk data diterima). Pada sebuah model, prinsip tersebut adalah sebuah variable hasil, sementara keputusan adalah hasil akhir dari proses pemikiran tentang suatu maslah atau problema untuk menjawab pertanyaan apa yang harus diperbuat guna mengatasi masalah tersebut, dengan menjatuhkan pilihan pada suatu alternative.

Dalam menyelesaikan permasalahan dengan metode MABAC ada beberapa langkah proses yang harus dipahami [6], [7], diantaranya :

1. Membentuk matriks keputusan awal (Forming initial decision matrix)

Langkah pertama yang dilakukan adalah mengevaluasi alternative " $m$ " dengan " $\mathrm{n}$ " kriteria. Alternatif disajikan dengan Vektor $A i=(x i 1, x i 2, x i 3, \ldots, x i n)$, dimana xij adalah nilai dari "I" alternative dengan kriteria "j" $(i=1,2,3, \ldots, n)$.

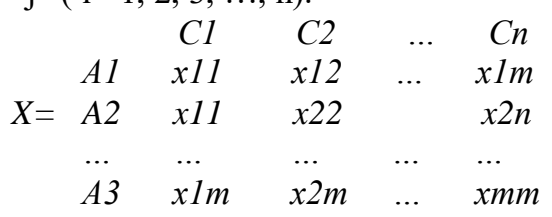

Dimana $\mathrm{m}$ adalah nomer alternative, $\mathrm{n}$ adalah jumlah total kriteria.

2. Normalisasi elemen matriks awal (x) (Normalization of initial matrix (x) elements).

$X=\begin{array}{ccccc} & C 1 & C 2 & \ldots & C n \\ A 1 & t 11 & t 12 & \ldots & t 1 m \\ \ldots & t 11 & t 22 & & t 2 n \\ A 3 & t 1 m & \ldots & \ldots & \ldots \\ & t 2 m & \ldots & t m m\end{array}$

Elemen matrik ternormalisasi $(\mathrm{N})$ diperoleh dengan menerapkan rumus:

1.Jenis kriteria keuntungan/benefit (For benefit type criteria)

$$
t_{i j=\frac{x_{i j-x_{i}}}{x_{i^{+-}-x_{i^{-}}}}}
$$

2.Jenis kriteria Biaya/Cost (For cost-type criteria)

$$
t_{i j=\frac{x_{i j}-x_{i^{+}}}{x_{i^{-}-x_{i^{+}}}}}
$$

Dimana $x i j, x i+$ dan $x i-$ menyajikan elemen-elemen matriks keputusan awal $(x)$, dimana, $x i+$ dan $x i-$ didefinisikan sebagai berikut:

$$
\begin{aligned}
& \mathrm{X}_{\mathrm{i}}{ }^{+}=\max (\mathrm{x} 1, \mathrm{x} 2, \mathrm{x} 3, \ldots, \mathrm{xm}) \text { mewakili nilai maksimum dari kriteria yang diamati oleh alternative. } \\
& \mathrm{x}^{-}=\max (\mathrm{x} 1, \mathrm{x} 2, \mathrm{x} 3, \ldots, \mathrm{xm}) \text { mewakili nilai minimum dari kriteria yang diamati oleh alternative. }
\end{aligned}
$$

3. Perhitungan elemen matriks tertimbang (V) (Calculation os weighted matriks (V) elements)

$$
\begin{array}{llll}
v 11 & v 12 \quad \ldots \quad v 1 m
\end{array}
$$


Journal of Computer System and Informatics (JoSYC)

Volume 3, No. 1, November 2021, Page 1-8

ISSN 2714-8912 (media online)

ISSN 2714-7150 (media cetak)

DOI 10.47065/josyc.v3i1.820

$$
V=\quad \begin{array}{cccr}
v 11 & v 22 & & v 2 n \\
\ldots & \ldots & \ldots & \ldots \\
v 1 m & v 2 m & \ldots & v m m
\end{array}
$$

Elemen matriks tertimbang $(\mathrm{V})$ dihitung berdasarkan rumus:

Keterangan:

$$
V i j=(w i * t i j)+w i
$$

$w i=$ menyajikan elemen matriks yang dinormalisasikan $(\mathrm{N})$

$t i j=$ menyajikan koefisien bobot kriteria

dengan menerapkan rumus (6) diperoleh matriks tertimbang (V), yang juga dapat ditulis sebagai berikut:

$$
V=\begin{array}{cccc}
w 1 * t 11+w 1 & w 2 * t 11+w 2 & \ldots & w n * t 1 n+w n \\
w 1 * t 21+w 1 & w 2 * t 22+w 2 & \ldots & w n * t 2 n+w n \\
\ldots & \ldots & \ldots & \ldots \\
w 1 * t m 1+w 1 & w 2 * t m 2+w 2 & \ldots & w n * m n+w n
\end{array}
$$

Dimana " $n$ ” menyajikan jumlah total kriteria, " $m$ ” menyajikan jumlah alternative.

4. Penentuan matriks area parkiraan perbatasan $(\mathrm{G})$ (Determination of border approximation area matriks $(G))$

Area perkiraan batas untuk setiap kriteria ditentukan sesuai dengan rumus:

$g_{i=}\left(\prod_{j=1}^{m} v_{i j}\right)^{1 / m}$

Dimana vij menampilkan elemen matriks berbobot (V). “ $m$ ”. menyajikan jumlah total alternative.

Setelah menghitung nilai gi berdasarkan kriteria, itu perbatasan $\mathrm{G}(9)$ dalam bentuk $n x l$ (" $n$ ” pemilihan alternative yang ditawarkan ) menyajikan jumlah total kriteria yang dilakukan.

$$
\begin{array}{lllll}
C 1 & C 2 & \ldots & C n
\end{array}
$$

$G=g 1 \quad g 2 \quad \ldots \quad g n$

5. Perhitungan elemen matriks jarak alternative dari daerah perkiraan perbatasan (Q) (Calculation of matriks elements of alternative distance from the border approximation).

$$
Q=\quad \begin{array}{cccc}
q 11 & q 12 & \ldots & q 1 m \\
q 21 & q 22 & & q 2 n \\
\ldots & \ldots & \ldots & \ldots
\end{array}
$$

Jarak alternative dari daerah perbatasan perkiraan (qij) tertimbang (V) dan nilai dari perkiraan ditentukan sebagai perbedaan elemen matriks perbatsan.

$$
Q=V-G
$$

Yang dapat ditulis dengan cara lain :

$$
\begin{array}{cccc}
w 11-g 1 & v 12-g 2 & \ldots & v 1 m-g n \\
w 12-g 1 & v 22-g 2 & \ldots & v 2 m-g n \\
\ldots & \ldots & \ldots & \ldots \\
W m 1-g 1 & v m 2-g 2 & \ldots & v m m-g n
\end{array}
$$

Dimana gi menyajikan daerah perkiraan perbatasan untuk kriteria $\mathrm{C} 1$, vij menyajikan elemen matriks berbobot (V), "n" menyajikan jumlah kriteria, "m" menyajikan nomor alternative. Alternatif Ai dapat termasuk ke area perkiraan perbatsan $(\mathrm{G})$, area perkiraan atas $\left(\mathrm{C}^{G^{+}}\right)$atau area perkiraan lebih rendah $\left(\mathrm{C}^{G^{-}}\right.$ ) yaitu, Ai $E\left\{\mathrm{G} \mathrm{V}^{+} \mathrm{v}^{G^{-}}\right)$. Daerah perkiraan atas $\left(\mathrm{C}^{+}\right)$menyajikan area dimana alternative ideal terletak $\left(\mathbf{A}^{+}\right)$, sedangkan area perkiraan yang lebih rendah $\left(G^{-}\right)$menyajikan area dimana alternative antiideal berada $\left(\mathbf{A}^{-}\right)$.

Milik $\boldsymbol{A}^{i}$ alternatif ke daerah perkiraan $\left(\mathrm{G}, G^{+}\right.$atau $\left.{ }^{G^{-}}\right)$ditentukan berdasarkan rumus.

$$
A_{i} \in\left\{\begin{array}{clc}
G^{+} & \text {if } & q_{i j}>0 \\
G & \text { if } & q_{i j}=0 \\
G & \text { if } & q_{i j}<0
\end{array}\right.
$$

Untuk dipilih sebagai yang terbaik dari set, alternative $A i$, harus termasuk ke daerah perkiraan atas $\left(G^{+}\right)$ dengan sebanyak mungkin kriteria.

6. Perengkingan Alternative ( Rangking alternative ).

Perhitungan nilai-nilai fungsi kriteria dengan alternative (14) diperoleh sebagai jumlah dari jarak alternative dari daerah perkiraan perbatasan (qi). Menjumlahkan elemen matriks Q dengan garis diperoleh nilai akhir dari fungsi kriteria alternative

$S_{i=} \sum_{j=1}^{n} q_{i j}, j=1,2, \ldots, n, i=1,2, \ldots, m$

Dimana " $n$ ” menyajikan jumlah kriteria, " $m$ ” menyajikan sejumlah alternative. 


\section{HASIL DAN PEMBAHASAN}

Sebelum merancang sebuah sistem perlu ada gambaran mengenai sistem yang sedang berjalan. Hal ini dimaksudkan agar memudahkan dalam melakukan apa yang diinginkan sehingga sistem berjalan sebagaimana mestinya. Dengan kata lain sistem lama dapat dijadikan sebagai perbandingan untuk merancang sistem baru nantinya. Analisa sistem merupakan penguraian dari suatu sistem informasi yang utuh kedalam bagian-bagian komponennya dengan maksud untuk mengidentifikasikan dan mengevaluasi permasalahan-permasalahan, kesempatan-kesempatan, hambatan-hambatan yang terjadi dan kebutuhan-kebutuhan yang diharapkan sehingga dapat diusulkan perbaikan-perbaikannya.

Setelah melakukan penelitian secara langsung kelapangan terhadap sistem yang sedang berjalan di LLDIKTI Wilayah I, yaitu pada sistem menentukan AKBID terbaik, sampai kepada laporan yang akan disajikan. Dimana sistem pengambilan keputusan menentukan Akademi Kebidanan terbaik masih dilakukan secara manual.

\subsection{Penerapan Metode MABAC}

Metode MABAC dikembangkan oleh Pamucar dan Cirovic. Dalam tulisan ini digunakan model hibrida, DEMATEL-MABAC, dimana metode DEMATEL digunakan untuk menentukan koefisien bobot kriteria dan metode MABAC digunakan untuk alternative peringkat. Metode yang digunakan untuk menentukan koefisien kriteria dan untuk peringkat alternatif. MABAC adalah tercermin dalam definisi jarak kriteria fungsi masingmasing alternatif yang diamati dari perbatasan daerah perkiraan. Menyelesaikan masalah dukungan keputusan yang digunakan pemilihan jaksa terbaik, dilakukan melalui beberapa langkah yang membuatnya proses ini termasuk mendefinisikan kriteria dan bobot kriteriaserta peringkat alternatif dan sensitivitas analisis hasil keluaran.Menentukan kriteria yang menjadi alternatifnya dievaluasi adalah salah satu segmen yang paling penting dari pengambilan keputusan.

Data penelitian yang digunakan adalah data sekunder yang diambil dari LLDIKTI wilayah I. Variabel penelitian yang digunakan berjumlah 4 variabel input, Variabel tersebut adalah sebagai berikut :

Tabel 1. Tabel Bobot Kriteria

\begin{tabular}{cccc}
\hline No & Kriteria & Persentase Bobot & Nilai \\
\hline 1 & K1 & 30 & 0,300 \\
2 & K2 & 30 & 0,300 \\
3 & K3 & 20 & 0,200 \\
4 & K4 & 20 & 0,200 \\
\hline
\end{tabular}

1. Proses pembentukan matriks keputusan awal (x) menentukan nilai matriks normalisasi sesuai dengan table fuzzy yang sudah ditentukan sebelumnya.

Tabel 2. Matriks Keputusan Awal (X)

\begin{tabular}{ccccc}
\hline \multirow{2}{*}{ Alternative } & \multicolumn{4}{c}{ Kriteria } \\
\cline { 2 - 5 } & $\mathrm{K} 1$ & $\mathrm{~K} 2$ & $\mathrm{~K} 3$ & $\mathrm{~K} 4$ \\
\hline Alternative 1 & 60 & 80 & 60 & 100 \\
Alternative 2 & 80 & 100 & 80 & 100 \\
Alternative 3 & 100 & 100 & 80 & 100 \\
Alternative 4 & 60 & 60 & 60 & 80 \\
Alternative 5 & 60 & 80 & 60 & 80 \\
Alternative 6 & 40 & 80 & 60 & 80 \\
Alternative 7 & 40 & 60 & 60 & 80 \\
\hline
\end{tabular}

2. Menentukan nilai matriks bobot normalisasi dengan cara menentukan terlebih dahulu jenis kriteria benefit dan coast. Selanjutnya menentukan nilai maximum dan minimum pada masing-masing kolom kriteria. Lakukan perhitungan dengan menggunakan rumus $(3,3)$, berikut perhitungan benefit dengan rumus :

$$
\begin{aligned}
& t_{i j=\frac{x_{i j-x_{i}}}{x_{i^{+}-x_{i^{-}}}}} \\
& \mathrm{A} 1=\frac{60-40}{100-40}=\frac{20}{60}=0,33 \frac{80-60}{100-60}=\frac{20}{40}=0,5 \frac{60-60}{80-60}=\frac{0}{20}=0 \frac{100-80}{100-80}=\frac{20}{20}=1 \\
& \mathrm{~A} 2=\frac{80-40}{100-40}=\frac{40}{60}=0,66 \frac{100-60}{100-60}=\frac{40}{40}=1 \frac{80-60}{80-60}=\frac{20}{20}=1 \frac{100-80}{100-80}=\frac{20}{20}=1 \\
& \mathrm{~A} 3=\frac{100-40}{100-40}=\frac{60}{60}=1 \frac{100-60}{100-60}=\frac{40}{40}=1 \frac{80-60}{80-60}=\frac{20}{20}=1 \frac{100-80}{100-80}=\frac{20}{20}=1 \\
& \mathrm{~A} 4=\frac{60-40}{100-40}=\frac{20}{60}=0,33 \frac{60-60}{100-60}=\frac{0}{40}=0 \frac{60-60}{80-60}=\frac{0}{20}=0 \frac{80-80}{100-80}=\frac{0}{20}=0
\end{aligned}
$$




$$
\begin{aligned}
& \mathrm{A} 5=\frac{60-40}{100-40}=\frac{20}{60}=0,33 \frac{80-60}{100-60}=\frac{20}{40}=0,5 \frac{60-60}{80-60}=\frac{0}{20}=0 \frac{80-80}{100-80}=\frac{0}{20}=0 \\
& \mathrm{~A} 6=\frac{40-40}{100-40}=\frac{0}{60}=0 \frac{80-60}{100-60}=\frac{20}{40}=0,5 \frac{60-60}{80-40}=\frac{0}{20}=0 \frac{80-80}{100-80}=\frac{0}{20}=0 \\
& \mathrm{~A} 7=\frac{40-40}{100-40}=\frac{0}{60}=0 \frac{60-60}{100-60}=\frac{0}{40}=0 \frac{60-60}{80-60}=\frac{0}{20}=0 \frac{80-80}{100-80}=\frac{0}{20}=0
\end{aligned}
$$

Tabel 3. Matriks Normalisasi Bobot Keputusan (N)

\begin{tabular}{lcccc}
\hline \multirow{2}{*}{ Alternative } & \multicolumn{4}{c}{ Kriteria } \\
\cline { 2 - 5 } & $\mathrm{K} 1$ & $\mathrm{~K} 2$ & $\mathrm{~K} 3$ & $\mathrm{~K} 4$ \\
\hline Alternative 1 & 0,33 & 0,5 & 0 & 1 \\
Alternative 2 & 0,66 & 1 & 1 & 1 \\
Alternative 3 & 1,00 & 1 & 1 & 1 \\
Alternative 4 & 0,33 & 0 & 0 & 0 \\
Alternative 5 & 0,33 & 0,5 & 0 & 0 \\
Alternative 6 & 0,00 & 0,5 & 0 & 0 \\
Alternative 7 & 0,00 & 0 & 0 & 0 \\
\hline
\end{tabular}

3. Proses menentukan bobot keputusan, matrik bobot kriteria (W) dikalikan dengan matriks normalisasi keputusan (N) selanjutnya dijumlahkan dengan bobot kriteria (W). Berikut perhitungan bobot keputusan dengan rumus :

$$
\begin{aligned}
& V i j=(w i * t i j)+w i \\
& \text { Alternative } 1 \\
& t_{1,1=}(0,3 * 0,33)+0,3=0,40 \\
& t_{1,2=}(0,3 * 0,5)+0,3=0,45 \\
& t_{1,3=}(0,2 * 0)+0,2=0,2 \\
& t_{1,4=}(0,2 * 1)+0,2=0,4
\end{aligned}
$$

Alternative 2

$t_{2,1=}(0,3 * 0,66)+0,3=0,50$

$t_{2,2}=(0,3 * 1)+0,3=0,6$

$t_{2,3}=(0,2 * 1)+0,2=0,4$

$t_{2,4}=(0,2 * 1)+0,2=0,4$

Alternative 3

$t_{3,1=}(0,3 * 1,00)+0,3=0,60$

$t_{3,2}=(0,3 * 1)+0,3=0,6$

$t_{3,3}=(0,2 * 1)+0,2=0,4$

$t_{3,4}=(0,2 * 1)+0,2=0,4$

Alternative 4

$t_{4,1=}(0,3 * 0,33)+0,3=0,40$

$t_{4,2}=(0,3 * 0)+0,3=0,3$

$t_{4,3}=(0,2 * 0)+0,2=0,2$

$t_{4,4=}(0,2 * 0)+0,2=0,2$

Alternative 5

$t_{5,1=}(0,3 * 0,33)+0,3=0,40$

$t_{5,2}=(0,3 * 0,5)+0,3=0,45$

$t_{5,3}=(0,2 * 0)+0,2=0,2$

$t_{5,4}=(0,2 * 0)+0,2=0,2$

Alternative 6

$t_{6,1=}(0,3 * 0,00)+0,3=0,30$

$t_{6,2=}(0,3 * 0,5)+0,3=0,45$

$t_{6,3}=(0,2 * 0)+0,2=0,2$

$t_{6,4=}(0,2 * 0)+0,2=0,2$

Alternative 7

$t_{7,1=}(0,3 * 0,00)+0,3=0,30$

$t_{7,2=}(0,3 * 0)+0,3=0,3$

$t_{7,3=}(0,2 * 0)+0,2=0,2$

$t_{7,4=}(0,2 * 0)+0,2=0,2$ 
Tabel 4. Matriks Bobot Keputusan (v)

\begin{tabular}{ccccc}
\hline \multirow{2}{*}{ Alternative } & \multicolumn{4}{c}{ Kriteria } \\
\cline { 2 - 5 } & $\mathrm{K} 1$ & $\mathrm{~K} 2$ & $\mathrm{~K} 3$ & $\mathrm{~K} 4$ \\
\hline Alternative 1 & 0,40 & 0,45 & 0,2 & 0,4 \\
Alternative 2 & 0,50 & 0,6 & 0,4 & 0,4 \\
Alternative 3 & 0,60 & 0,6 & 0,4 & 0,4 \\
Alternative 4 & 0,40 & 0,3 & 0,2 & 0,2 \\
Alternative 5 & 0,40 & 0,45 & 0,2 & 0,2 \\
Alternative 6 & 0,30 & 0,45 & 0,2 & 0,2 \\
Alternative 7 & 0,30 & 0,3 & 0,2 & 0,2 \\
\hline
\end{tabular}

4. Menentukan nilai matriks batas $(G)$ rumus untuk menentukan nilai matriks batas $(G)$ setiap kriteria seperti pada rumus no $(3,8)$. Lakukan perkalian terhadap nilai pada masing-masing kriteria yang sama, maka total perkalian selanjutnya dipangkatkan dengan satu per jumlah alternative. Penyelesainnya sebagai berikut :

$$
\begin{aligned}
& g_{i=}\left(\prod_{j=1}^{m} v_{i j}\right)^{1 / m} \\
& \mathrm{~K} 1=(0,40 * 0,50 * 0,60 * 0,40 * 0,40 * 0,30 * 0,30)^{1 / 7}=0,4032 \\
& \mathrm{~K} 2=(0,45 * 0,6 * 0,6 * 0,3 * 0,45 * 0,45 * 0,3)^{1 / 7}=0,4353 \\
& \mathrm{~K} 3=(0,2 * 0,4 * 0,4 * 0,2 * 0,2 * 0,2 * 0,2)^{1 / 7}=0,2439 \\
& \mathrm{~K} 4=(0,4 * 0,4 * 0,4 * 0,2 * 0,2 * 0,2 * 0,2)^{1 / 7}=0,2693
\end{aligned}
$$

Tabel 5. Nilai Matriks $\operatorname{Batas}(G)$

\begin{tabular}{ccccc}
\hline \multirow{2}{*}{ Alternative } & \multicolumn{4}{c}{ Kriteria } \\
\cline { 2 - 5 } & $\mathrm{K} 1$ & $\mathrm{~K} 2$ & $\mathrm{~K} 3$ & $\mathrm{~K} 4$ \\
\hline $\mathrm{G}_{\mathrm{i}}$ & 0,4032 & 0,4353 & 0,2439 & 0,2693 \\
\hline
\end{tabular}

5. Perhitungan elemen matriks jarak alternative dari daerah perkiraan perbatasan (Q) untuk menentukan nilai dari elemen matriks jarak alternative batas berdasarkan matriks daerah perkiraan batas $(\mathrm{G})$ dengan menggunakan rumus $(3,11)$ yaitu :

$Q=V-G$

$Q_{1,1=0,40 * 0,4032=0,1613}$

$Q_{1,2}=0,45 * 0,4353=0,1958$

$Q_{1,3}=0,2 * 0,2439=0,0487$

$Q_{1,4}=0,4 * 0,2693=0,1077$

$Q_{2,1}=0,50 * 0,4032=0,2016$

$Q_{2,2}=0,6 * 0,4353=0,2611$

$Q_{2,3}=0,4 * 0,2439=0,0975$

$Q_{2,4}=0,4 * 0,2693=0,1077$

$Q_{3,1}=0,60 * 0,4032=0,2419$

$Q_{3,2}=0,6^{*} 0,4353=0,2611$

$Q_{3,3}=0,4 * 0,2439=0,0975$

$Q_{3,4}=0,4 * 0,2693=0,1077$

$Q_{4,1}=0,40 * 0,4032=0,1613$

$Q_{4,2}=0,3 * 0,4353=0,1305$

$Q_{4,3}=0,2 * 0,2439=0,0487$

$Q_{4,4}=0,2 * 0,2693=0,0538$

$Q_{5,1}=0,40 * 0,4032=0,1613$

$Q_{5,2}=0,45 * 0,4353=0,1958$

$Q_{5,3}=0,2 * 0,2439=0,0487$

$Q_{5,4}=0,2 * 0,2693=0,0538$

$Q_{6,1}=0,30 * 0,4032=0,1210$

$Q_{6,2}=0,45^{*} 0,4353=0,1958$

$Q_{6,3}=0,2 * 0,2439=0,0487$

$Q_{6,4}=0,2 * 0,2693=0,0538$

$Q_{7,1}=0,30 * 0,4032=0,1210$

$Q_{7,2}=0,3 * 0,4353=0,1305$

$Q_{7,3}=0,2 * 0,2439=0,0487$ 
Journal of Computer System and Informatics (JoSYC)

Volume 3, No. 1, November 2021, Page 1-8

ISSN 2714-8912 (media online)

ISSN 2714-7150 (media cetak)

DOI 10.47065/josyc.v3i1.820

$$
Q_{7,4=} 0,2 * 0,2693=0,0538
$$

Tabel 6. Elemen Matriks jarak alternative dari daerah perbatasan Q)

\begin{tabular}{ccccc}
\hline \multirow{2}{*}{ Alternative } & \multicolumn{4}{c}{ Kriteria } \\
\cline { 2 - 5 } & $\mathrm{K} 1$ & $\mathrm{~K} 2$ & $\mathrm{~K} 3$ & $\mathrm{~K} 4$ \\
\hline Alternative 1 & 0,1613 & 0,1958 & 0,0487 & 0,1077 \\
Alternative 2 & 0,2016 & 0,2611 & 0,0975 & 0,1077 \\
Alternative 3 & 0,2419 & 0,2611 & 0,0975 & 0,1077 \\
Alternative 4 & 0,1613 & 0,1305 & 0,0487 & 0,0538 \\
Alternative 5 & 0,1613 & 0,1958 & 0,0487 & 0,0538 \\
Alternative 6 & 0,1210 & 0,1958 & 0,0487 & 0,0538 \\
Alternative 7 & 0,1210 & 0,1305 & 0,0487 & 0,0538 \\
\hline
\end{tabular}

6. Perengkingan alternative (S) untuk menentukan nilai perengkingan alternative diselesaikan dengan rumus $(3,14)$ penyelesainnya sebagai berikut :

$S_{i=} \sum_{j=1}^{n} q_{i j}, j=1,2, \ldots, n, i=1,2, \ldots, m$

Alternative $1=0,1613+0,1958+0,0870+0,1077=0,5137$

Alternative $2=0,2016+0,2611+0,1160+0,1077=0,6681$

Alternative $3=0,2419+0,2611+0,1160+0,1077=0,7084$

Alternative $4=0,1613+0,1305+0,0580+0,0538=0,3945$

Alternative $5=0,1613+0,1958+0,0870+0,0538=0,4598$

Alternative $6=0,1210+0,1958+0,0870+0,0538=0,4195$

Alternative $7=0,1210+0,1305+0,0580+0,0538=0,3542$

Tabel 7. Perengkingan Alternative (S)

\begin{tabular}{ccc}
\hline Alternative & S & Rank \\
\hline Alternative1 & 0,5137 & 3 \\
Alternative2 & 0,6681 & 2 \\
Alternative3 & 0,7084 & 1 \\
Alternative4 & 0,3945 & 6 \\
Alternative5 & 0,4598 & 4 \\
Alternative6 & 0,4195 & 5 \\
Alternative7 & 0,3542 & 7
\end{tabular}

Dari hasil perengkingan di atas maka yang layak sebagai AKBID terbaik adalah alternative 3 yaitu :

Tabel 8. Data alternative yang layak sebagai AKBID terbaik

\begin{tabular}{ccccc}
\hline \multirow{2}{*}{ Alternative } & \multicolumn{4}{c}{ Kriteria } \\
\cline { 2 - 5 } & K1 & K2 & K3 & K4 \\
\hline Alternative 3 & 31 dosen & A & B & Sehat \\
\hline
\end{tabular}

\subsection{Implementasi Program}

Tampilan berikut merupakan tampilan menu perhitungan. Menu ini merupakan menu yang berguna untuk menampilkan perhitungan penilaian alternative dan kriteria. Tampilan menu penilaian kriteria dapat dilihat pada gambar 1.

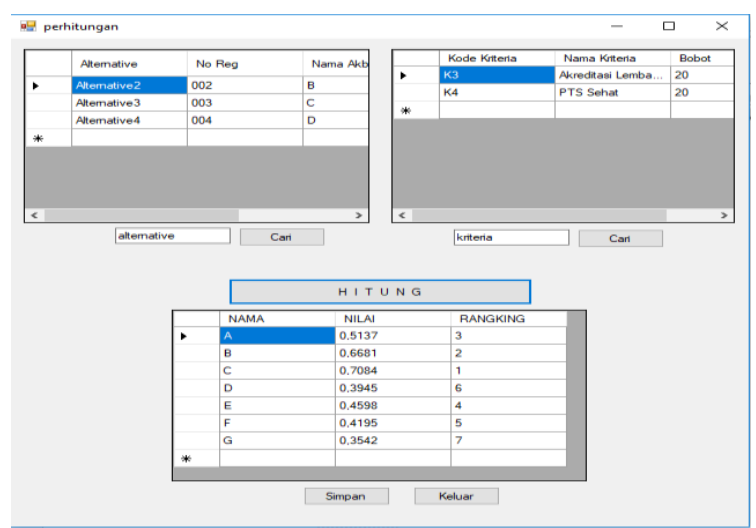

Gambar 1. Form Perhitungan 
Journal of Computer System and Informatics (JoSYC)

Volume 3, No. 1, November 2021, Page 1-8

ISSN 2714-8912 (media online)

ISSN 2714-7150 (media cetak)

DOI 10.47065/josyc.v3i1.820

\section{KESIMPULAN}

Berdasarkan dari penelitian yang telah peneliti lakukan pada bab-bab sebelumnya, maka dapat diambil kesimpulan Dalam suatu sistem pendukung keputusan terutama untuk melakukan penentuan akademi kebidanan terbaik ini dihitung berdasarkan beberapa nilai kriteria. Dengan menggunakan metode multi attribute border approximation area comparison (MABAC) di nilai dapat menyelesaikan permasalahan dalam penentuan akademi kebidanan terbaik di LLDIKTI Wil I Sumut khususnya di kota medan, maka yang menjadi akademi kebidanan terbaik adalah akademi kebidanan helvetia medan. Perancangan sistem penentuan akademi kebidanan di LLDIKTI Wil I Sumut memiliki hasil yang lebih efisien dan akurat karena proses penentuannya di lakukan dengan sistem sehingga hasilnya lebih tepat dan cepat, terlebih dapat membantu LLDIKTI Wil I Sumut dalam mengambil keputusan.

\section{REFERENCES}

[1] J. E. and L. T. P. Turban, A. Efraim, Decision Support System and Intelegence Systems, 7th ed. Jogjakarta: Penerbit Andi, 2015.

[2] T. Limbong et al., Sistem Pendukung Keputusan: Metode \& Implementasi. Medan: Yayasan Kita Menulis, 2020.

[3] R. K. Hondro, "MABAC: Pemilihan Penerima Bantuan Rastra Menggunakan Metode MultiAttributive Border Approximation Area Comparison," J. Mahajana Inf., vol. 3, no. 1, pp. 41-52, 2018.

[4] D. Nofriansyah, Multi Criteria Decision Making (MCDM) Pada Sistem Pendukung Keputusan. Yogyakarta: CV.Budi Utama, 2017.

[5] D. Nofriansyah, Konsep Data Mining Vs Sistem Pendukung Keputusan. 2015.

[6] N. Ndruru, M. Mesran, F. T. Waruwu, and D. P. Utomo, "Penerapan Metode MABAC Untuk Mendukung Pengambilan Keputusan Pemilihan Kepala Cabang Pada PT . Cefa Indonesia Sejahtera Lestari," RESOLUSI Rekayasa Tek. Inform. dan Inf., vol. 1, no. 1, pp. 36-49, 2020.

[7] F. Laila and N. A. Hasibuan, "Pemilihan Pengangkatan Karyawan Tetap Menerapkan Metode Multi-Attributive Border Approximation Area Comparison," vol. 1, no. 1, pp. 5-12, 2021. 